This is the author's version of a work that was accepted for publication in Journal of cleaner production (Elsevier). Changes resulting from the publishing process, such as peer review, editing, corrections, structural formatting, and other quality control mechanisms may not be reflected in this document. Changes may have been made to this work since it was submitted for publication. A definitive version was subsequently published in Journal of cleaner production, vol 66, March 2014, p. 588-598. DOI 10.1016/j.jclepro.2013.10.055

\title{
Environmental assessment of different pipelines for drinking water transport and distribution network in small to medium cities: a case from Betanzos, Spain
}

David Sanjuan-Delmás ${ }^{\mathrm{a}}$; Anna Petit-Boix ${ }^{\mathrm{a}}$; Carles M. Gasol ${ }^{\mathrm{b}}$; Gara Villalba ${ }^{\mathrm{a}, \mathrm{c}}$; María Eugenia Suárez-Ojedac; Xavier Gabarrella,c; Alejandro Josa ${ }^{\mathrm{d}, \mathrm{e}}$; Joan Rieradevalla,c

a Sostenipra, Institute of Environmental Sciences and Technology (ICTA), School of Engineering, Universitat Autònoma de Barcelona (UAB), Campus UAB, 08193 Bellaterra, Barcelona, Spain.

'Inèdit innovació. Spin off of UAB Research park. Cabrils Road Km 2(IRTA) 08348, Cabrils, Barcelona, Spain.

'Department of Chemical Engineering, Universitat Autònoma de Barcelona (UAB), Campus UAB, 08193 Bellaterra, Barcelona, Spain.

dDepartment of Geotechnical Engineering and Geosciences, School of Civil Engineering, Technical University of Catalonia - Barcelona Tech, Campus Nord, C/Jordi Girona 1-3, Building D2, 08034 Barcelona, Catalonia, Spain

e Institute of Sustainability (IS.UPC), Technical University of Catalonia-Barcelona Tech, UPC, Campus Nord, Building VX. PI. Eusebi Güell, 6, 08034 Barcelona, Catalonia, Spain

Corresponding author: David Sanjuan-Delmás, Sostenipra, Institute of Environmental Sciences and Technology (ICTA), School of Engineering Universitat Autònoma de Barcelona (UAB), Campus UAB, 08193 Bellaterra, Barcelona, Spain. Phone number: (34)935813760 Email: david.sanjuan@uab.cat

Word count: 8249 


\begin{abstract}
Until now, few studies had focused on the environmental impact of the construction phase of a drinking water transport and distribution network (DWTDN). Using the life cycle assessment (LCA) methodology, this article compares the environmental impact of pipes made of different materials as constructive solutions for the DWTDN. Two pipe diameters (90 and $200 \mathrm{~mm}$ ) commonly used in small to medium-sized cities are analysed. The results show that polyvinyl chloride (PVC), high density polyethylene (HDPE) and low density PE have similar environmental impacts in the case of $90 \mathrm{~mm}$ pipe diameter. In the case of $200 \mathrm{~mm}$ pipe diameter, ductile iron (DI) and glass fibre reinforced polyester show higher environmental impacts than HDPE and PVC, which in the case of DI are between 3 and 11 times higher than those of HDPE for all the midpoint impact categories. Regarding the different construction phases, installation has a higher percentage of environmental impact for $90 \mathrm{~mm}$ pipe diameter (40 to 68\% for HDPE in all the impact categories) than for $200 \mathrm{~mm}$ pipe diameter ( 24 to $57 \%$ for an HDPE) due to the difference in the amount of material required for the manufacture of the pipe. The assessment methodology was applied to calculate the environmental burdens derived from a case study. The impact of the different elements of the case study network has been added to obtain the global impact. The potential reduction of the environmental impacts of the case study has been calculated substituting the whole actual network by less impacting constructive solutions. A potential reduction of between 6 and $16 \%$ of the impact has been found for the case study, although the savings might be greater in networks with greater abundance of more impacting pipe materials such as DI. This methodology allows the improvement of the network and the design of more eco-efficient DWTDN.
\end{abstract}

Keywords: network; pipe material; LCA; urban infrastructure; eco-efficiency; construction 


\section{Introduction}

\subsection{Cities and Urban Water Cycle}

Water is a major priority all over the world because of its importance for life. Because water needs are dependent on population and activities, the urban water cycle (UWC) is a crucial flow in urban areas (UNESCO, 2012), were the density of population is high. Almost every village and town in the developed world manages its own UWC, generating very different impacts depending on factors such as the demand, water availability, the location of the net elements and topography, etc. These factors must be considered when assessing the UWC to reduce its environmental impacts and to preserve the environment. This is an important issue because some global patterns show that to supply water to cities, new and different infrastructures as well as the renewal of obsolete infrastructures might be necessary.

The urban population of the world is forecasted to grow from 3.4 billion in 2009 to 6.3 billion people in 2050 (UNSECO, 2012). Urban growth will be equal to all of the world population growth over this period plus some net moves from the current rural population. New urban areas with water needs will appear, and the global water demand will increase. These new areas will generate an increase in the water demand and infrastructures. Furthermore, because of the effects of climate change, new uncertainties are arising with regard to freshwater supplies and the main water use sectors, such as agriculture and energy, exacerbating uncertainties regarding future demands for water (UNEP, 2012). These facts will make it necessary to optimise water cycle infrastructures and the better use of water resources, for example, reducing the loss of water due to leakages in the network or using alternative water sources such as rainwater harvesting.

Water scarcity is already a major problem in the world. There are several examples of overexploitation of groundwater and rivers, which depletes water resources (UNESCO, 2012). This is relevant considering the social, economic and ecological importance of the UWC. Figure 1 shows the basic stages of the UWC, water as a natural resource in the environment, water treatment, consumption and the interphases between each of the previous stages, including the drinking water transport and distribution network (DWTDN). 


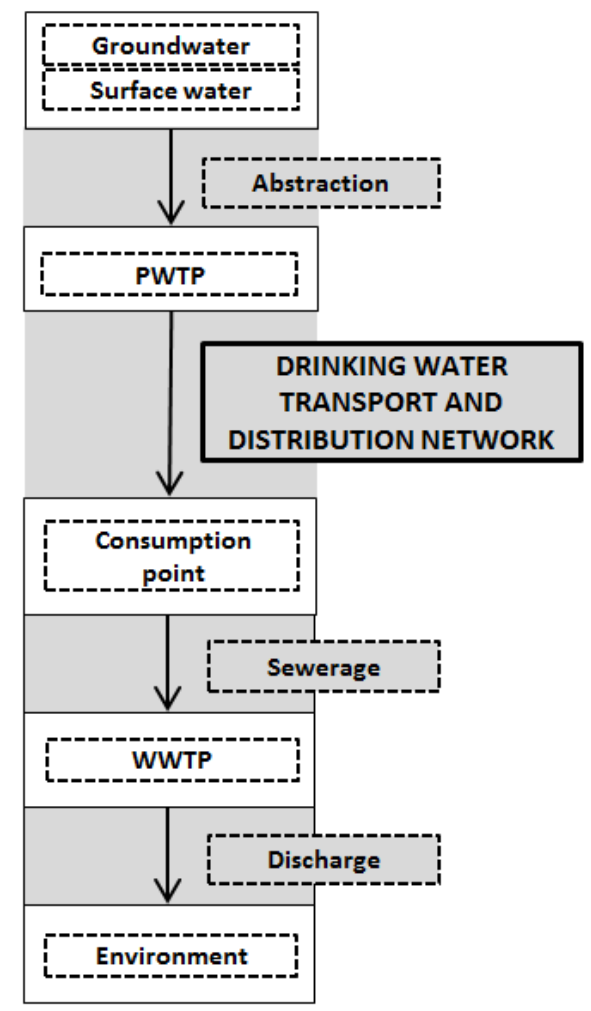

PWTP: Potable Water Treatment Plant

WWTP: Waste Water Treatment Plant

Figure 1. Position of the DWTDN within the UWC

\subsection{Environmental studies in the water network}

Growing challenges are increasing the complexity of the UWC. Globally, the most important pressures on the water cycle are raising populations, climate uncertainty, drought and floods. To make well-informed choices facing these challenges, policy, design and management options must be considered in future studies (Fagan et al., 2010). Therefore, the sustainability of the life cycle of UWC infrastructures must be assessed to determine possible improvements in the present infrastructure as well as in future construction projects.

Few studies have analysed the environmental impact of the whole UWC from a life cycle assessment (LCA) perspective. Venkatesh and Brattebø (2011), focused on the operation and maintenance phases of the UWC, and their results show that wastewater treatment is the most impactful element ( $88 \%$ of the aggregated impact). Arpke and Hutzler (2006), however, showed that water heating in households is the main energy consumer and an important contributor to the environmental impact.

The weight each phase has on the environmental impact depends on the specific case considered. The results from Stokes and Horvath (2006), which implemented a life cycle energy assessment, show that operation (including water pumping) was the phase that contributes the most (60 to $91 \%$ of the global impact), followed by maintenance (5 to $36 \%$ ), whereas construction had the least impact (4 to $5 \%$ ). Similar results were found in other studies (Stokes and Horvath, 2009; 2011). This shows that the critical or more impacting phase can change depending on factors that should be analysed.

Different functional units (FUs) have been considered in previous studies to assess the UWC. The environmental impact per cubic meter of the water supplied has been studied by several authors (Lassaux et al., 2007; Muñoz et al., 2010; Amores et al., 
2013). Other FUs used are one-year operations of the network (Venkatesh and Brattebø, 2011) and the provision of water and sanitation infrastructure to a given number of new households (Friedrich et al., 2009).

Because of the growing concern of climate change and the priority to act on this issue, some articles have focused on the Global Warming Potential (GWP) impact category. For example, Sharma et al. (2009) calculated the greenhouse gases (GHG) emissions of providing water services for 86,000 residents. Their results show that between 16 and $25 \mathrm{t}$ of $\mathrm{CO}_{2}$ eq. per year were generated. In a similar study, Friedrich et al. (2009) show that for 200,000 residents, between 5.8 and $10 \mathrm{t}$ of $\mathrm{CO}_{2}$ eq. per year were generated. Muñoz et al. (2010) calculated the GHG emission from the whole infrastructure and obtained values between 1.5 and $2.5 \mathrm{~kg}$ of $\mathrm{CO}_{2}$ eq. $/ \mathrm{m}^{3}$ supplied.

\subsection{Environmental studies in drinking water transport and distribution infrastructures}

Within the UWC, this article is focused on the DWTDN. Previous studies have calculated the contribution of the DWTDN (including energy to pump water) to the UWC. This represents between 20 and $40 \%$ of the environmental impacts of the UWC (Amores et al., 2013) and around 20\% (Lemos et al, 2013); both for 7 out of 9 impact categories. These results should encourage further study on the distribution network; however, as stated in the previous section, these results vary depending on the specific case.

The DWTDN consists of a series of stages the water covers until the consumption point. As shown in Figure 1, after being treated at the PWTP, water is transported through the DWTDN to the consumption points around the urban area. The DWTDN is formed of a network of pipes and other individual components (e.g., valves and hydrants) that transfer the potable water from the PWTP to the consumption point.

Pipes are the most characteristic feature of the DWTDN. The use of pipes made of one or another material might generate variations on the environmental impacts derived from the constructive solution. Data from water pipes (for the whole UWC) show on one hand that in France, UK, Germany, Sweden and Switzerland, cast iron is the most common material, used in more than $50 \%$ of the grid. On the other hand, plastic is the most common material in the Netherlands (more than 50\%), and steel is the most common in Italy (approximately 35\%) (Graty, 2007). In Spain, the main materials being installed at the moment are reinforced concrete, ductile iron (DI), polyethylene (PE), polyvinyl chloride (unplasticised) (PVC-U), steel, PVC with molecular orientation (PVCO) and glass fibre reinforced polyester (GFRP) (CEDEX, 2009).

Focusing on the GWP, the GHG emissions derived from pipes made of different materials has been compared. Dennison et al. (1999) analysed the production of DI and medium density PE, concluding that the main contributor to the GHG emissions was the manufacturing of the pipe. Piratla et al. (2012) calculated the GHG emissions considering the embodied energy in the materials and concluding that PVC-O had lower emissions than PVC, high density PE (HDPE) and DI.

This article compares the environmental impact of pipes made of different materials and considers the installation of the pipe and the transport in the assessment. Similarly, the present study aims to conduct an assessment of the DWTDN considering the whole constructive solution but for different pipe materials and diameters. The 
materials and energy required for the production, transport and installation of the network will be included within the study (Figure 2). The results will allow design or redesign DWTDN by taking into account environmental criteria.

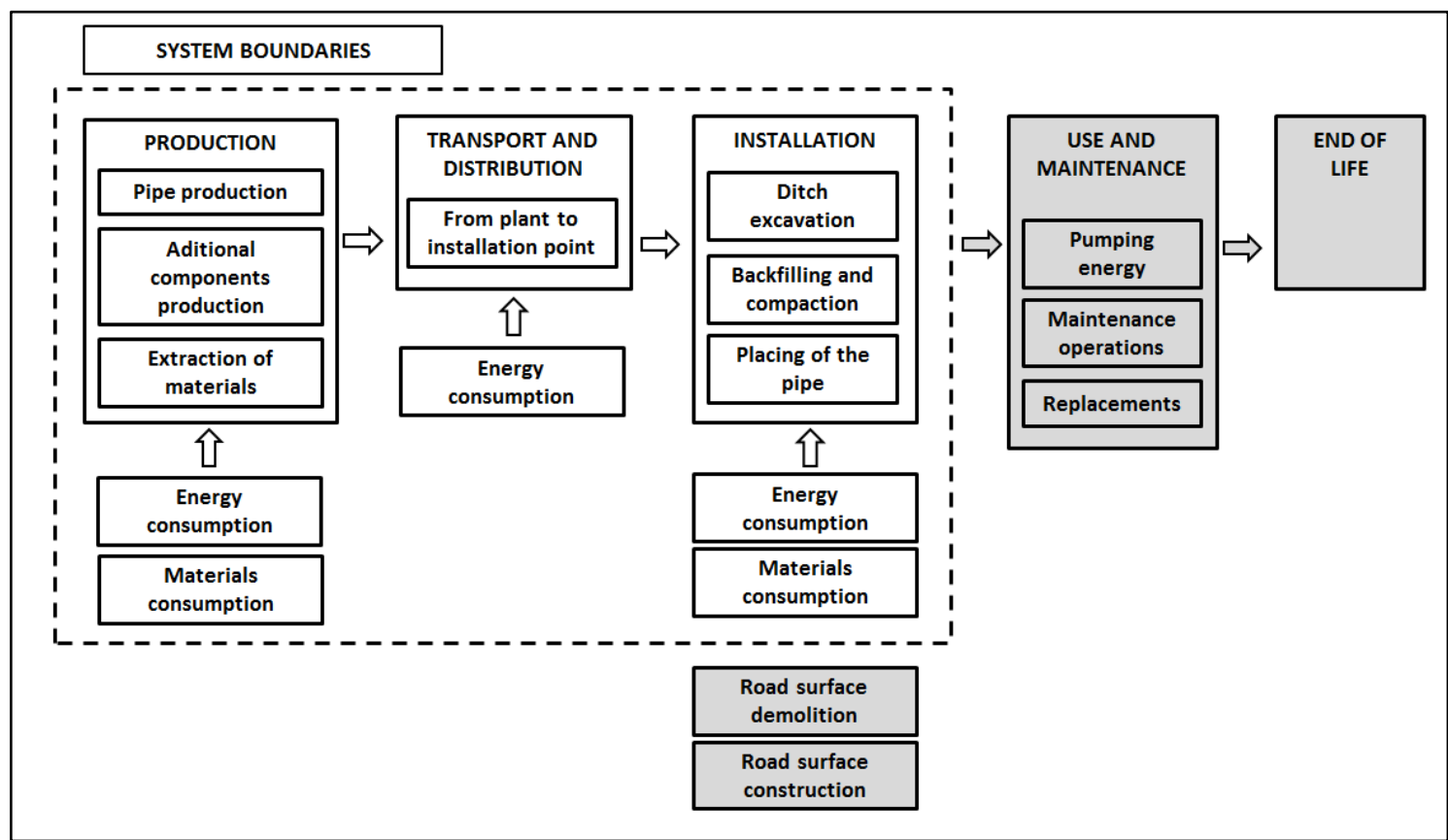

Figure 2 Diagram of the DWTDN life cycle and boundaries of the system. The grey phases are outside the scope of this study.

The DWTDN is usually buried in cities. For the installation, a ditch is excavated to place the pipe, and the ditch is refilled once the pipe is placed completing the installation.

The use phase is characterised by the electricity consumption to pump the water through the network. A study in PWTP in Toronto showed that pumping the water in and out the plant accounted for $73 \%$ of the GHG emissions (Racoviceanu et al., 2007), although results from other studies on the same topic show a much lower impact (5\%) (Vince et al., 2008). Piratla et al. (2012) estimated that the water pumping generated up to $98 \%$ of the GHG emissions, and thus, the environmental impact of the life cycle for pipes made of different materials did not present relevant differences. In the case of Venkatesh and Brattebø (2011), the energy for pumping accounted for $17.2 \%$ of the global energy consumption for supplying water. These great variations occur because energy consumption is influenced by factors such as the difference of the height between the city and the PWTPs, the pressure of the grid and the efficiency of the pumps. Thus, it is necessary to assess the infrastructure of the DWTDN by focusing on the construction to clearly visualise the variations only on the environmental impacts from the use of different solutions. This is the approach adopted in the study and the use and maintenance phase have been excluded (Figure 2).

The lifetime and failure of the pipes (due to aging) is an important issue to consider, especially in stagnating grids, where most of the environmental impact comes from the maintenance and replacement of pipes (Venkatesh and Brattebø, 2011; 2012). A possible approach for calculating this phase is the use of the standard values of pipe breakage (Piralta et al., 2012). Once the life of the pipe has lapsed, the network is rarely dismantled for the DWTDN, and the grid is usually left hibernating (Adequa, 2012). Although the hibernating network generates environmental impacts such as soil occupation or material mobilisation, these impacts are considered negligible in 
comparison with those derived from the other phases, since no energy is consumed and no relevant emissions are generated.

\section{Materials and methods}

\subsection{Objectives}

This article determines the best environmental alternatives for the DWTDN of small to medium cities or neighbourhoods and evaluates the environmental impact of a DWTDN. The specific objectives are:

- To elaborate an inventory of the materials, machinery and energy consumption in the production, transport and installation phases of the life cycle of the DWTDN.

- To compare the environmental impact of different constructive solutions for DWTDNs considering different pipe materials to determine what the less impactful constructive alternatives are.

- To assess the environmental impact of individual components of the network (pipes, valves, hydrants, etc.) to calculate the environmental impacts of a medium city' network.

- To assess the environmental impacts of the DWTDN in a case study to validate the proposed method and to estimate the potential environmental improvements.

\subsection{Declared unit}

The declared unit (DU) is used instead of the functional unit when the precise function of the product or scenario is not stated or is unknown. In this case, for a given length of network, the amount of water transported will vary depending on the diameter of the pipe (the exact function is unknown).

The water distribution system consists of the combination of different pipe diameters and other intermediate elements, which are chosen according with technical parameters. However, for the comparison, it must be considered that pipes with larger diameters or/and made for higher pressures can transport greater flows of water. Because the DU must be related to the quantity of water transported (which is the function fulfilled), the diameters and pressures the pipes are made for must be equal to fulfil the same DU. Pipes from the same material can hold different maximum pressures (depending on their thicknesses). Thus, a maximum pressure for which all the pipes compared are manufactured for must be selected. Two diameters commonly used in small to medium cities have been selected. Similar diameters have been used in previous studies (Dennison et al., 1999; Piratla et al., 2012).

The DU considered to compare the environmental impacts of the constructive solutions has been selected according to the environmental product declaration (EPD) for construction products (EN 15804). The DU is the production, transport and installation of a lineal meter of network with a pipe $90 \mathrm{~mm}$ in diameter and a maximum pressure of 6 bar or a pipe $200 \mathrm{~mm}$ in diameter and a maximum pressure of $10 \mathrm{bar}$, including the accessories of the pipe and the backfilling and bedding materials, required to transport drinking water over the course of 50 years. Apart from the diameter, the maximum 
pressure and the life expectancy, further technical characteristics are not important for the declaration of technical equivalency.

\subsection{Data sources}

The database from the Institute of Technology of Catalonia (Metabase Itec, 2010) includes data about construction processes. The quantity of materials for each constructive solution as well as the type of machinery for the installation and its consumptions were obtained from this source.

The environmental information related with the processes involved with materials, energy and transport used is from the ecoinvent 2.2 database (ecoinvent, 2009).

Regarding the ditch dimensions and the installation procedure, handbooks from constructor enterprises were consulted (Adequa, 2010; Prefabricados Delta, 2012). Furthermore, the Spanish normative was consulted (CEDEX, 2009), and experts on the subject from Agbar (c) (Barcelona' water management company) were interviewed (Agbar, 2013). Table 1 summarizes the data sources used.

For the transport, a distance of $100 \mathrm{~km}$ was considered for all materials except for gravel, for which $30 \mathrm{~km}$ was selected, since it is abundant and long distances are not common. These distances have already been considered previously (Mendoza et al., 2012; Oliver-Solà et al., 2009).

The data for the case study (Betanzos, Spain) were provided by (Agbar, 2013) from its databases CONTEC (CONTEC @ , 2012) and GISAgua (GISAgua $@$, 2012).

Table 1. Summary of the data obtained from each data source

\begin{tabular}{|c|l|}
\hline Source & \multicolumn{1}{c|}{ Data obtained } \\
\hline Metabase Itec, 2010 & $\begin{array}{l}\text { Quantity of materials }(\mathrm{kg} / \text { lineal } \mathrm{m} \text { of network) } \\
\text { Diesel consumption }(\mathrm{MJ} / \mathrm{h}) \text { and working hours }(\mathrm{h}) \text { for } \\
\text { machinery }\end{array}$ \\
\hline ecoinvent 2.2 database & $\begin{array}{l}\text { Environmental impacts of materials extraction, } \\
\text { production and transport. }\end{array}$ \\
\hline $\begin{array}{c}\text { Adequa, 2010; Prefabricados } \\
\text { Delta, 2012; CEDEX, 2009 }\end{array}$ & Dimensions of the ditch. \\
\hline
\end{tabular}

All the environmental information is taken from the same database, allowing the comparability of the different pipe materials. Credits on the recycling at the end of life of DI are not taken into account.

\subsection{Environmental impacts}

The LCA methodology was applied to determine the environmental impacts. The software Simapro 7.3 (PRé Consultants, 2010) has been used.

According to the EPD of construction products (EN 15804), the following 7 midpoint impact categories from the CML 2 baseline 2000 were included in the assessment: abiotic depletion potential (ADP), acidification potential (AP), eutrophication potential (EP), global warming potential (GWP), ozone layer depletion (OLDP) and photochemical oxidation (PCOP). Additionally, the Cumulative Energy Demand (CED) was included. 


\subsection{Methodology}

\subsubsection{Environmental impact assessment of constructive solutions}

The following commonly used pipe materials in small to medium cities have been selected for the study: PVC, HDPE, low density PE (LDPE) and DI. GFRP was also considered because it is being increasingly introduced in piping systems (Faria and Guedes, 2010), and its environmental performance is of interest. The accessories (additional pieces of the pipes) and the pipes are made from the same material in all cases and are considered together in the inventory (Supplementary table A). The unions are all made from synthetic rubber.

The potential life expectancy of the pipe for each material is being studied, but few reliable data can be found. Experts argue that PVC, HDPE, LDPE and DI could reach 100 years of life expectancy. However, a life expectancy of more than 50 years would imply high needs of maintenance and preservation of the pipe, including anticorrosion treatments, among other measures (AWWA, 2010; 2011). Moreover, the life expectancy of the pipes might be shortened by fluctuations in the grid pressure (Agbar, 2013). Thus, life expectancy also depends on the management of the DWTDN. For this reason, the assumption that all the pipes have the same life span (50 years) has been adopted for the assessment.

For the installation phase, the DWTDN can be placed on the surface or buried. In accordance with the common practice in small to medium cities (Adequa, 2009), only buried networks installed through the excavation of a ditch will be considered. Figure 3 shows the main steps of the installation.

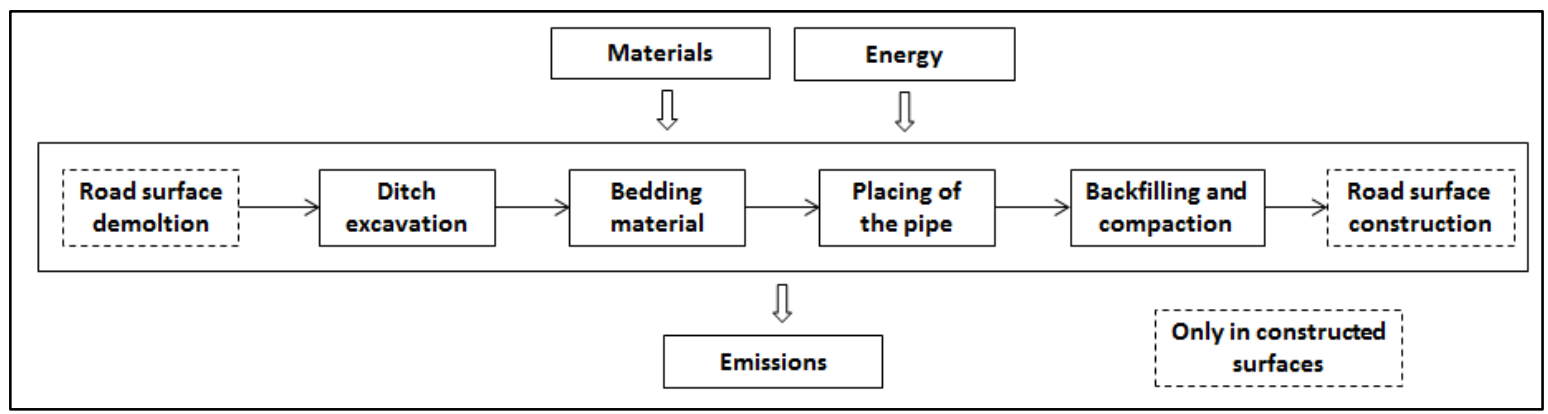

Figure 3. Main steps of the installation of the DWTDN

Within this phase, the materials and energy for the excavation and backfilling of the ditch as well as for the placing of the pipe were considered (Figure 2). The road surface construction and demolition were excluded from the analysis because they are the same for all cases and can be very different in each situation. Table 2 summarises the data on the ditch found in construction enterprises handbooks. 
Table 2. Review of the characteristics of the ditch for the installation of the DWTDN.

\begin{tabular}{|c|c|c|c|c|c|c|c|}
\hline & \multirow{2}{*}{ Source } & \multirow{2}{*}{$\begin{array}{l}\text { Minimum } \\
\text { width of } \\
\text { the ditch } \\
\text { (m) }\end{array}$} & \multirow{2}{*}{$\begin{array}{l}\text { Minimum } \\
\text { depth of } \\
\text { the ditch } \\
\text { (m) }\end{array}$} & \multicolumn{2}{|c|}{ Backfilling } & \multicolumn{2}{|c|}{ Supporting bed } \\
\hline & & & & $\begin{array}{l}\text { Maximum } \\
\varnothing(\mathrm{mm})\end{array}$ & $\begin{array}{c}\text { Backfilling } \\
\text { material }\end{array}$ & $\begin{array}{c}\text { Minimum } \\
\text { thickness (cm) }\end{array}$ & $\begin{array}{l}\text { Bedding } \\
\text { material }\end{array}$ \\
\hline $\begin{array}{l}90 \mathrm{~mm} \\
\text { pipes }\end{array}$ & $\begin{array}{c}\text { Adequa } \\
\text { Uralita, } \\
2010\end{array}$ & $0.8^{1}$ & $\begin{array}{c}\mathrm{PD}+\mathrm{SBT}+ \\
\left(1^{2} / 0.6^{3}\right)\end{array}$ & 15 & $\begin{array}{l}\text { Sand, } \\
\text { coarse } \\
\text { aggregate }\end{array}$ & $10+0.1 \varnothing$ & $\begin{array}{l}\text { Gravel, sand } \\
\text { or crushed } \\
\text { stone. }\end{array}$ \\
\hline $\begin{array}{c}200 \mathrm{~mm} \\
\text { pipes }\end{array}$ & $\begin{array}{c}\text { Adequa } \\
\text { Uralita, } \\
2010\end{array}$ & $0.8^{1}$ & $\begin{array}{c}\mathrm{PD}+\mathrm{SBT}+ \\
\left(1^{2} / 0.6^{3}\right)\end{array}$ & 30 & $\begin{array}{l}\text { Sand, } \\
\text { coarse } \\
\text { aggregate }\end{array}$ & $10+0.1 \varnothing$ & $\begin{array}{l}\text { Gravel, sand } \\
\text { or crushed } \\
\text { stone. }\end{array}$ \\
\hline
\end{tabular}

${ }^{1}$ CEDEX, 2009; ${ }^{2}$ with traffic; ${ }^{3}$ without traffic (sidewalk)

$\mathrm{PD}=$ Pipe diameter, $\mathrm{SBT}=$ Supporting bed thickness

In all cases, the wall of the ditch was considered to be completely vertical. The depth and width of the ditch and the thickness of the bed from Table 2 were maintained. A depth of $1 \mathrm{~m}$ to the upper point of the pipe was considered, and it was assumed that the pipes are placed under traffic because this is the most impactful option. Gravel was chosen as bedding material and sand as backfilling material in all the cases. Figure 4 shows the dimensions of the ditches for the two diameters of pipes considered (section 2.3).

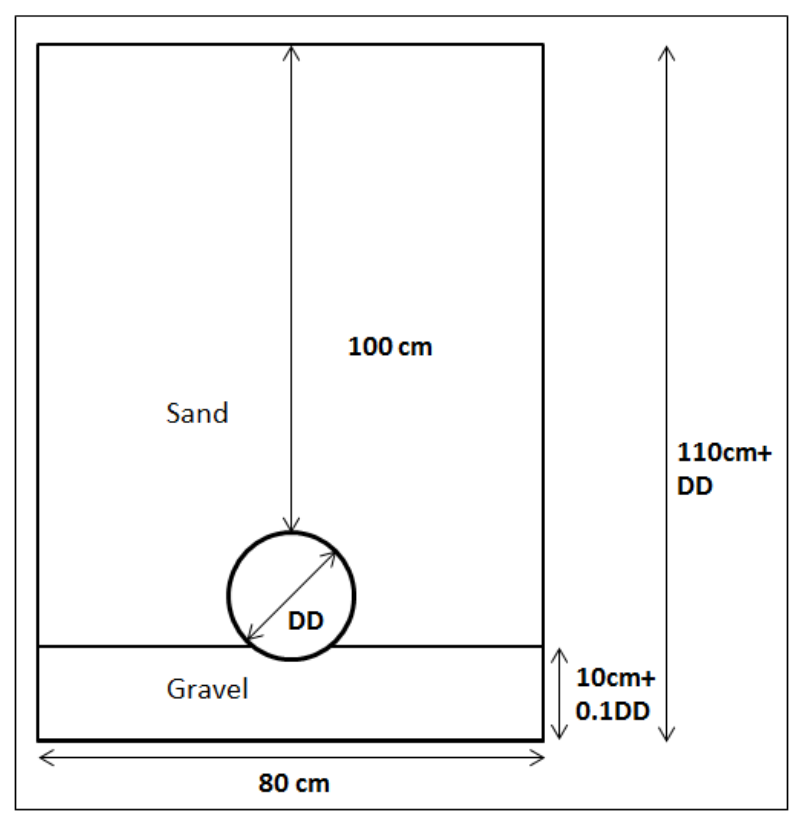

$\mathrm{DD}=$ Ditch Diameter

Figure 4. Dimensions of the ditch for 90 and $200 \mathrm{~mm}$ pipes.

Regarding the machinery used in the installation phase, Table 3 shows the different machines considered and their consumptions. 
Table 3. Machinery used in the installation phase and their energy consumption.

\begin{tabular}{|l|c|l|}
\hline \multicolumn{1}{|c|}{ Machine } & Consumption (MJ/h) & \multicolumn{1}{c|}{ Energy source } \\
\hline Backhoe excavator & 432.12 & Diesel \\
\hline Double drum vibrator road roller & 60.86 & Diesel \\
\hline Vibrating tamper & 60.86 & Diesel \\
\hline
\end{tabular}

Source: Metabase Itec, 2010

As stated in section 1.3, the phases of use and end of use were excluded from the assessment (Figure 2). For the comparison of the pipes, only variations higher than $5 \%$ will be considered.

\subsubsection{Environmental impact of the individual elements of the network}

Some individual components of the network are analysed (hydrants, pumps and valves) (Supplementary table B).

Hydrants include their register well, and a standard connection diameter of $100 \mathrm{~mm}$ was selected to estimate the environmental impact. For shut-off valves, 2 standard connection diameters of 50 and $100 \mathrm{~mm}$ were selected.

For the components, no reliable data about their lifespans were found, and the same data as those of the pipe were considered (50 years). A different life expectancy of the elements of the network would significantly vary the environmental impact of the network.

\subsubsection{Environmental impact of a DWTDN}

The assessment of the DWTDN of a municipality requires data about the materials and diameters of the pipes and the length of each type of pipe, as well as data about the individual elements. The use of geographical information system (GIS) technologies is needed to obtain these data.

The first stage of the assessment consists of calculating the environmental impact per lineal meter of network for each type of pipe and for each of the punctual elements of the DWTDN following the methodology used in the assessment of the constructive solutions (section 2.5.1). The environmental impact of each type of pipe is multiplied by its length in the network and the impact of the individual elements is multiplied by the number of elements in the network. The environmental impacts of the DWTDN are obtained adding the environmental impacts of all the elements.

For the case study (Betanzos, Spain), the network within the buildings is not considered. Also the sorts of pipes that represent less than $1 \%$ of the network have been excluded from the analysis because they do not represent a significant part of the impact. Additionally, the potential of the improvement of the DWTDN of Betanzos has been calculated. The potential has been assessed assuming that the entire network is made of the best constructive solutions found in the comparison. The difference between the actual environmental impacts and the impacts calculated for this hypothetic grid is the potential of improvement of the DWTDN. 


\section{Results and discussion}

\subsection{Comparison of the environmental impact of the different pipes}

A comparison of the constructive solutions reveals differences between the environmental impacts derived from each solution. Figure 5 shows the comparison of the environmental impact for constructive solutions with $90 \mathrm{~mm}$ diameter pipes. PVC and HDPE have similar environmental impacts, but PVC is around 10\% less impacting for ADP, PCOP and CED. LDPE is the most impacting solution, having between 5 and $25 \%$ higher impact than HDPE in 5 out of 7 impact categories.

The same ditch dimensions are considered for the 3 cases; for this reason, the phases of transport and installation have similar environmental impacts. The differences in the impact are derived from the production phase. LDPE has higher environmental burdens (per kg) than HDPE and PVC in 4 out of the 7 impact categories. Furthermore, the LDPE option requires a higher amount of material to manufacture the pipe than the other options (up to $90 \%$ more than PVC).

A sensitivity analysis focused in the GWP impact category (Figure 6) reveals that the differences between the environmental impacts of these constructive solutions are not great enough to consider one environmentally preferable, since variations of 10 years in the lifespan of one pipe material makes it less impacting than the rest.

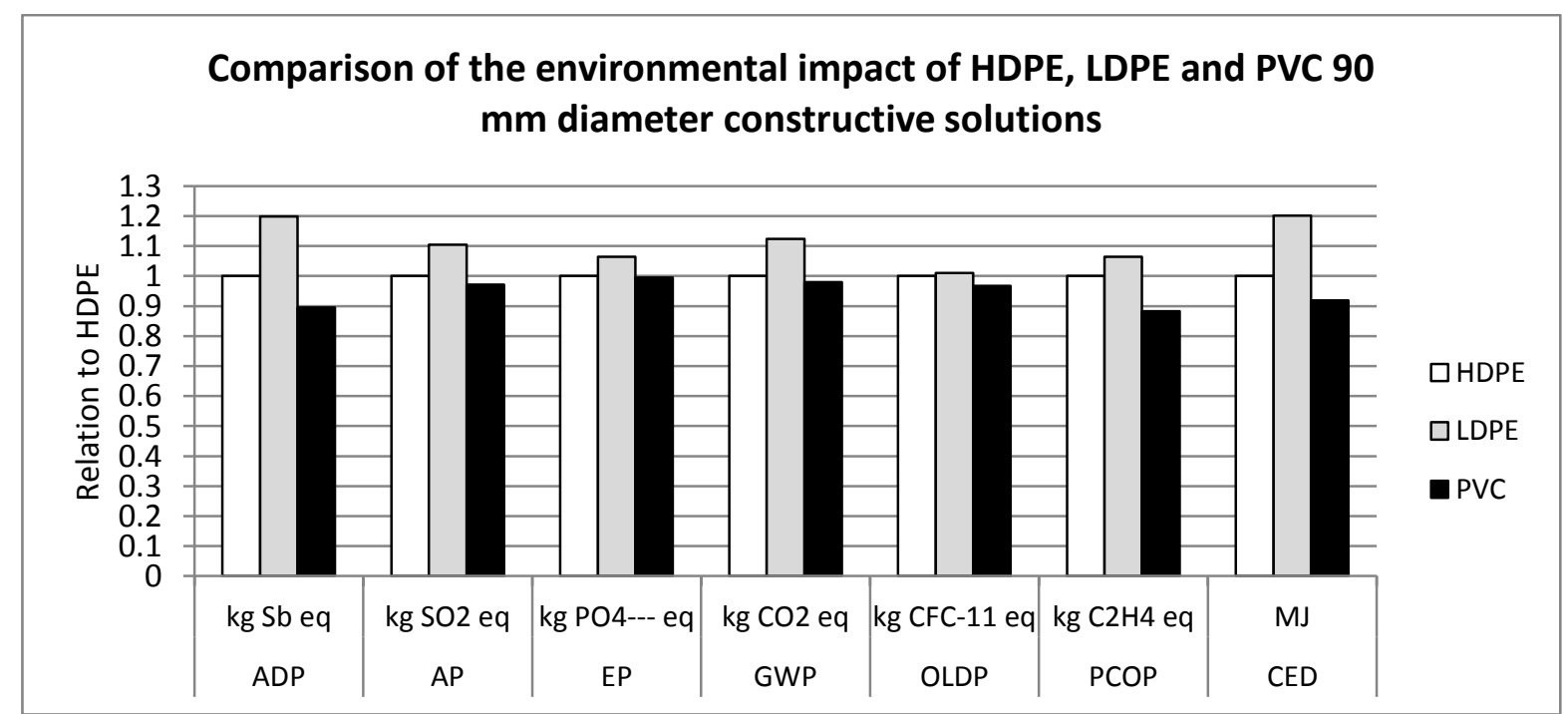

Figure 5. Comparison of the environmental impact of $90 \mathrm{~mm}$ diameter constructive solutions HDPE=high density polyethylene, LDPE= low density polyethylene, $\mathrm{PVC}=$ poly vinyl chloride 


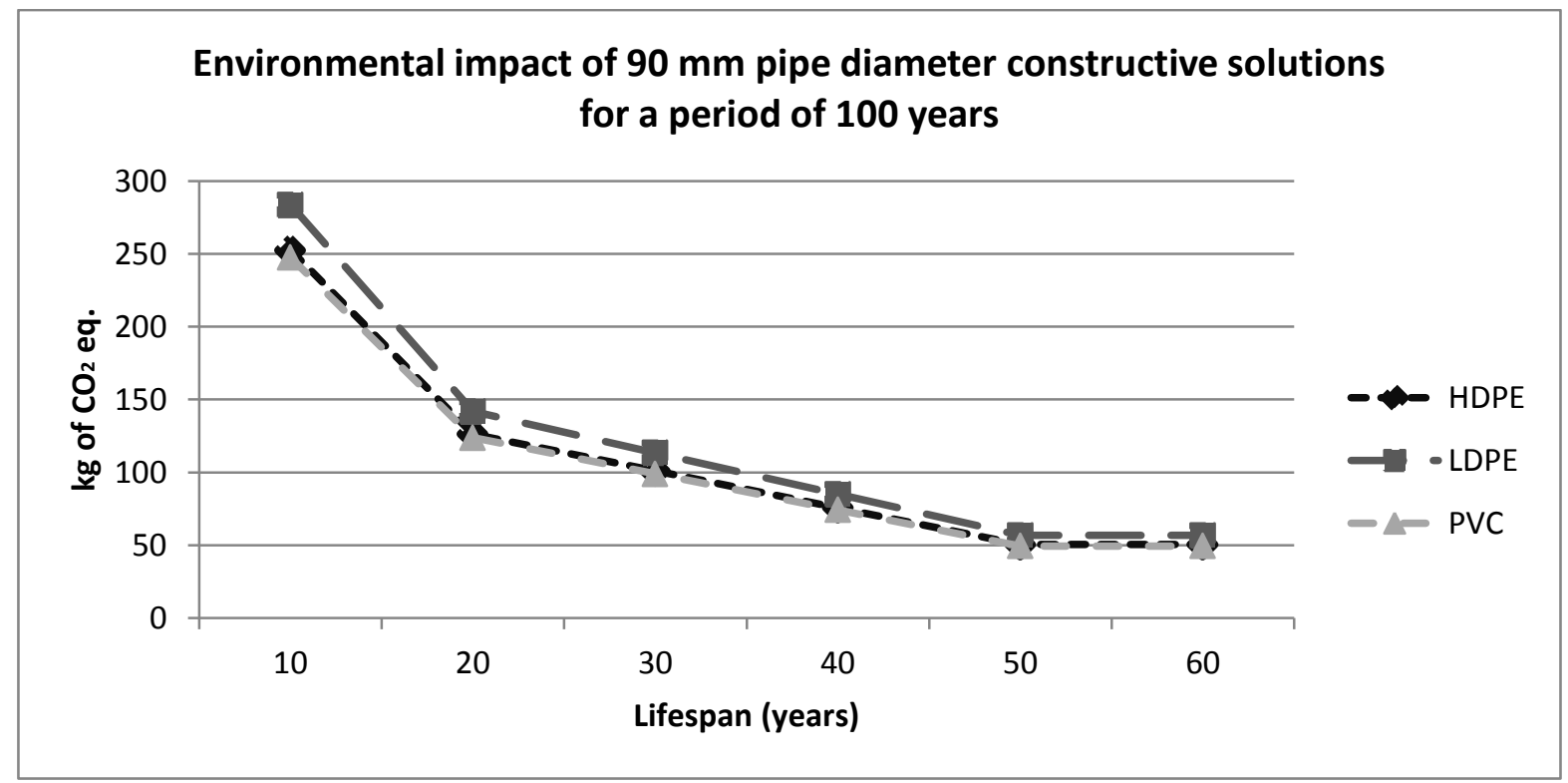

Figure 6. Sensitivity analysis for the environmental impact of $90 \mathrm{~mm}$ pipe diameter constructive solutions for a period of 100 years

$\mathrm{HDPE}=$ high density polyethylene, $\mathrm{LDPE}=$ low density polyethylene, $\mathrm{PVC}=$ poly vinyl chloride

These results are different from those for $200 \mathrm{~mm}$ diameter pipes (Figure 7). In this case, HDPE and PVC present the lowest environmental impacts, between a 40 and $90 \%$ lower impact than DI and GFRP. This is because DI and GFRP pipes are made with higher amounts of material $(4.76 \mathrm{~kg} / \mathrm{m}$ of $P V C$ vs. $36.3 \mathrm{~kg} / \mathrm{m}$ of DI). The differences between the environmental impacts of HDPE and PVC are similar to these observed for $90 \mathrm{~mm}$ constructive solutions (PVC is between 0 and $20 \%$ less impacting).

DI presents the highest environmental impacts in all impact categories and an impact up to 12 times greater than that of HDPE. The environmental impact of GFRP is between 45 and $75 \%$ lower than that of $\mathrm{DI}$ in 6 out of 7 impact categories. Nevertheless, if further research proves that the lifespan of DI and GFRP pipes is greater than that of PVC and HDPE, the results would be much favourable for DI and GFRP. To have lower impacts, the life span of DI should be from 3 to 11 times that of PVC, whereas GFRP should have 2 to 2.5 times the PVC life expectancy.

The results of the CED contrasted with those from Piratla et al. (2012), which show that the embodied energy of the PVC pipe was slightly higher than that of DI and HDPE. This is because Piratla et al. only compared the embodied energy of the material, whereas in this study also the manufacturing energy has been considered. The manufacturing energy represents a greater percentage for the DI pipe (35 to 50\% in all impact categories) than for the HDPE pipe (less than 10\%).

The sensitivity analysis focused on the GWP impact category (Figure 8) reveals in this case that the environmental impact of GFRP might be similar to the impact of HDPE and PVC with small variations (10 years) in the lifespan. Again, the differences are not great enough to consider one environmentally preferable. 


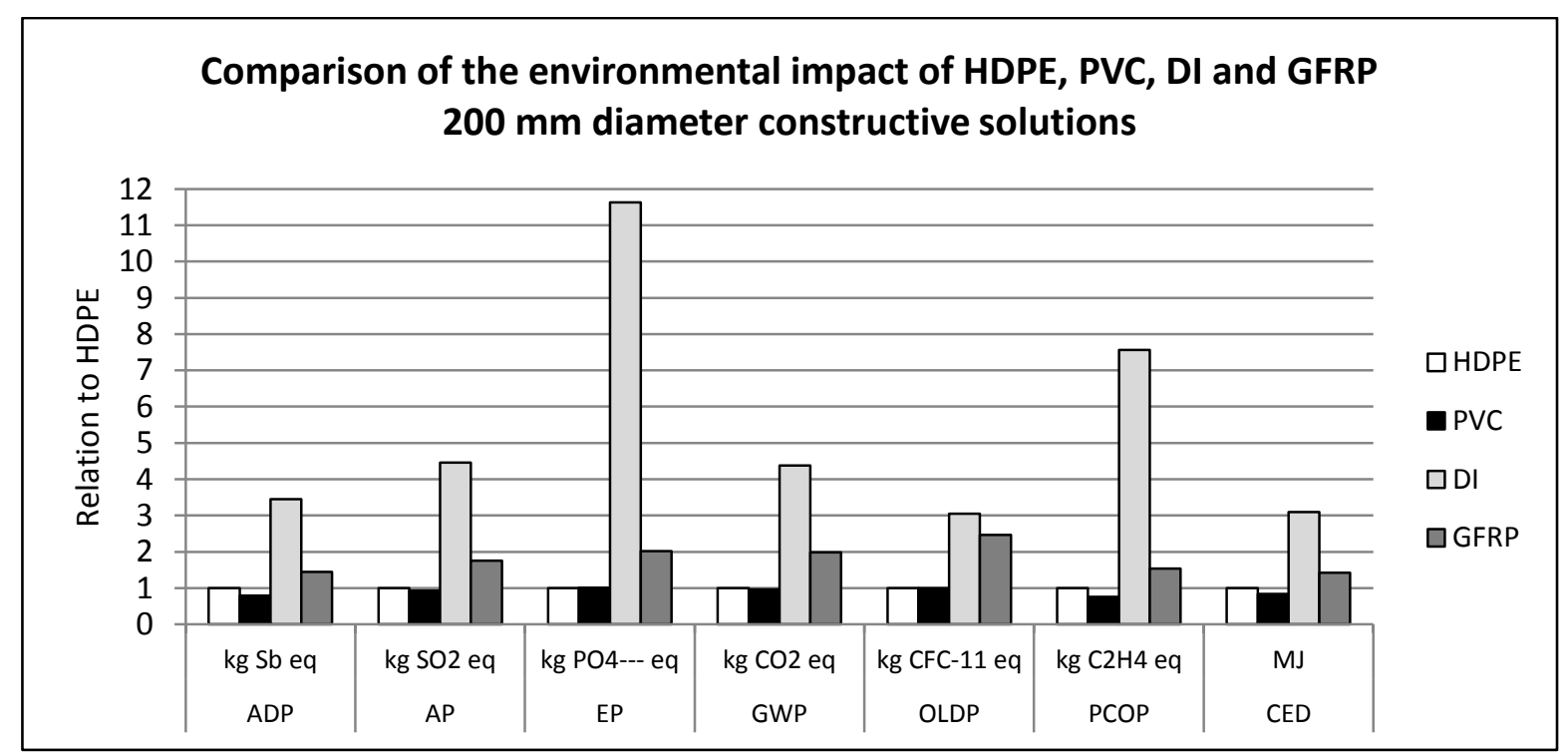

Figure 7. Comparison of the environmental impact of $200 \mathrm{~mm}$ diameter constructive solutions $\mathrm{HDPE}=$ high density polyethylene, $\mathrm{PVC}=$ poly vinyl chloride, $\mathrm{DI}=$ ductile iron, $\mathrm{GFRP}=$ glass fibre reinforced polyester

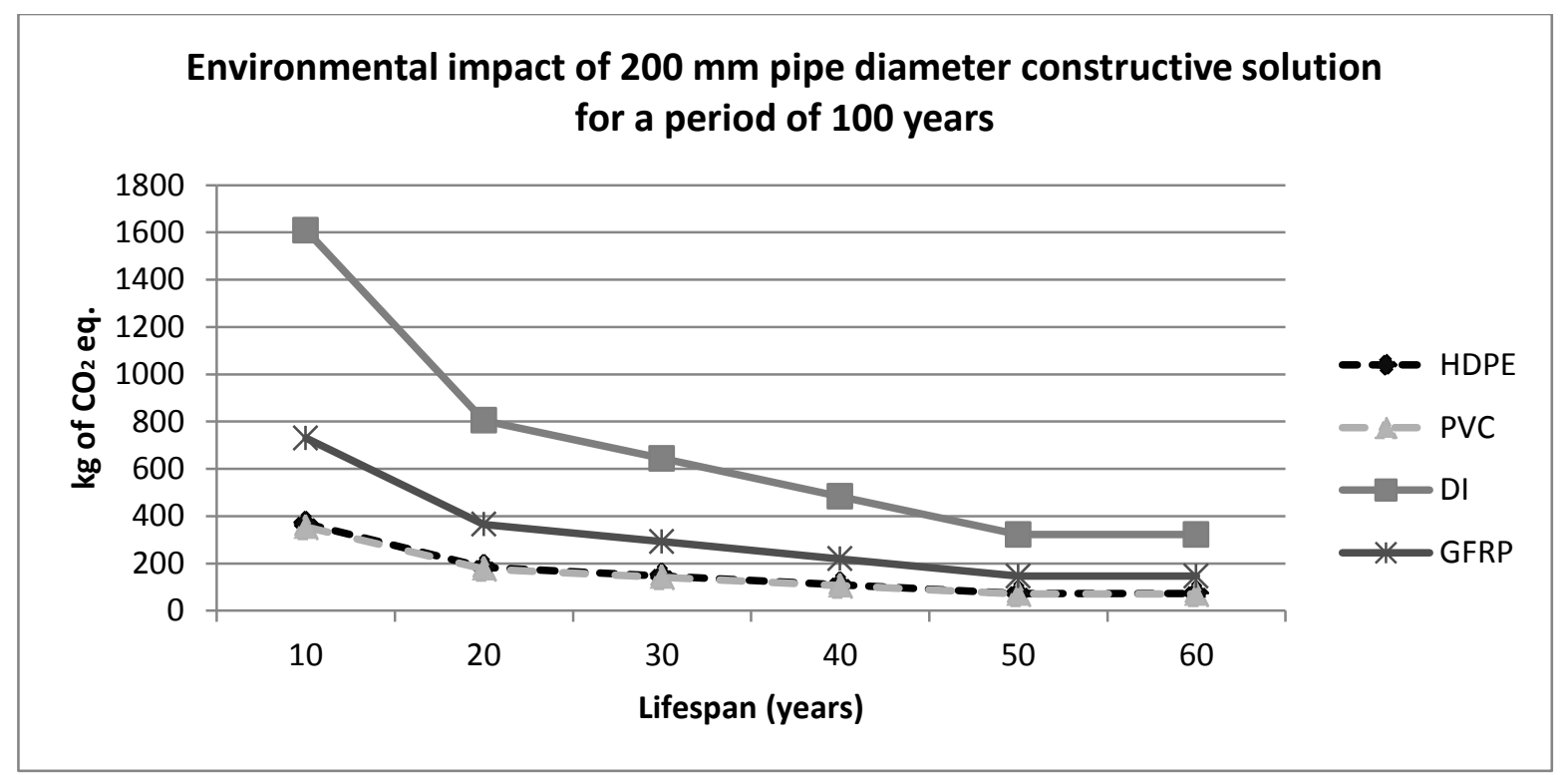

Figure 8. Sensitivity analysis for the environmental impact of $200 \mathrm{~mm}$ pipe diameter constructive solutions for a period of 100 years

$\mathrm{HDPE}=$ high density polyethylene, $\mathrm{PVC}=$ poly vinyl chloride, $\mathrm{DI}=$ ductile iron, $\mathrm{GFRP}=$ glass fibre reinforced polyester

It must be considered that pipes can be deficient if they are not properly installed. In such case, the environmental impacts increase, since further operations are required to fix or replace the deficient network. Future research analysing the percentages of deficient pipes for each pipe material could influence the results.

Another point to consider is that the pipe might not reach its end of life. In cities, it is common to rebuild some streets to refurbish them and modify urban planning, among other reasons. Thus, the constructive solution could be changed in a shorter period than expected. This factor would favour the use of less impactful pipes even if they have a shorter lifespan because they may not reach their end of life. 
Furthermore, the management of the network at its end of life is an important point. Studies about "urban mining" are already taking place (Krook et al., 2010), and in the future, the pipe materials might be recovered instead of left hibernating. This is especially relevant for the case of $\mathrm{DI}$, since it can be easily recovered and sold.

\subsection{Environmental impact of the life cycle phases}

Figure 9 shows the contribution of each life cycle stage to the environmental impact of the $90 \mathrm{~mm}$ diameter pipes. The figure shows that the 3 pipes show similar percentages in most of the impact categories.

The phase of installation, including the materials for the backfilling of the trench, is the main contributor, with more than $40 \%$ of the impact in 5 out of 7 impact categories for the 3 options. This highlights the importance of analysing the whole constructive solution instead of only the pipe, especially for small pipe diameters. Otherwise, a great part of the environmental impact is omitted. Transport contributes between 20 and $40 \%$ of the impact and production between 10 and $20 \%$ in all the impact categories. Thus, transport and production are also relevant phases of the environmental impact.

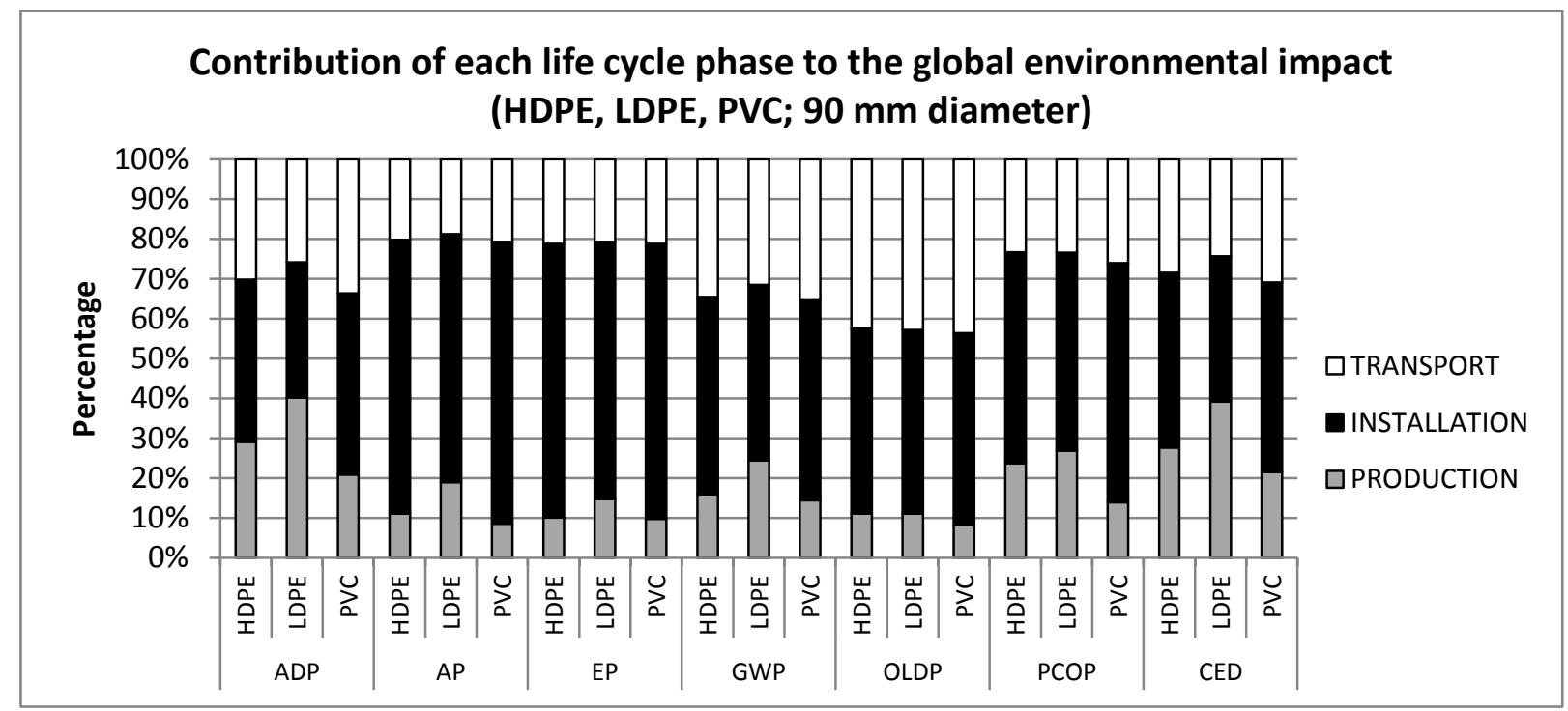

Figure 9. Contribution of each life cycle stage to the environmental impact of $90 \mathrm{~mm}$ diameter pipes.

$\mathrm{HDPE}=$ high density polyethylene, $\mathrm{LDPE}=$ low density polyethylene, $\mathrm{PVC}=$ poly vinyl chloride

Figure 10 shows the contribution of each life cycle phase for $200 \mathrm{~mm}$-diameter pipes. In contrast with the previous comparison, production is the main contributor to the environmental impact.

For DI and GFRP, production represents more than $60 \%$ of the impact in all impact categories because of the high environmental burdens of these materials in comparison with other impacts of the life cycle, such as the energy consumption in installation.

For HDPE and PVC, production represents more than $35 \%$ of the impact in 4 out of 7 impact categories. This is a significantly higher percentage than in the case of $90 \mathrm{~mm}$ diameters for the same material. Because the considered ditch is very similar (only 11 $\mathrm{cm}$ deeper), the increase in the amount of material of the pipe (approximately 3.5 times greater) results in an increase of the percentage that the production phase represents. 
This shows that the percentage of contribution of each life cycle phase is related to the diameter of the pipe because higher diameters require more materials, which increases the percentage of the impact due to production.

The installation phase is also relevant for HDPE and PVC, representing $20-55 \%$ of the impact in all impact categories. Transport has minor relevance, representing between $5-40 \%$ of the environmental impact.

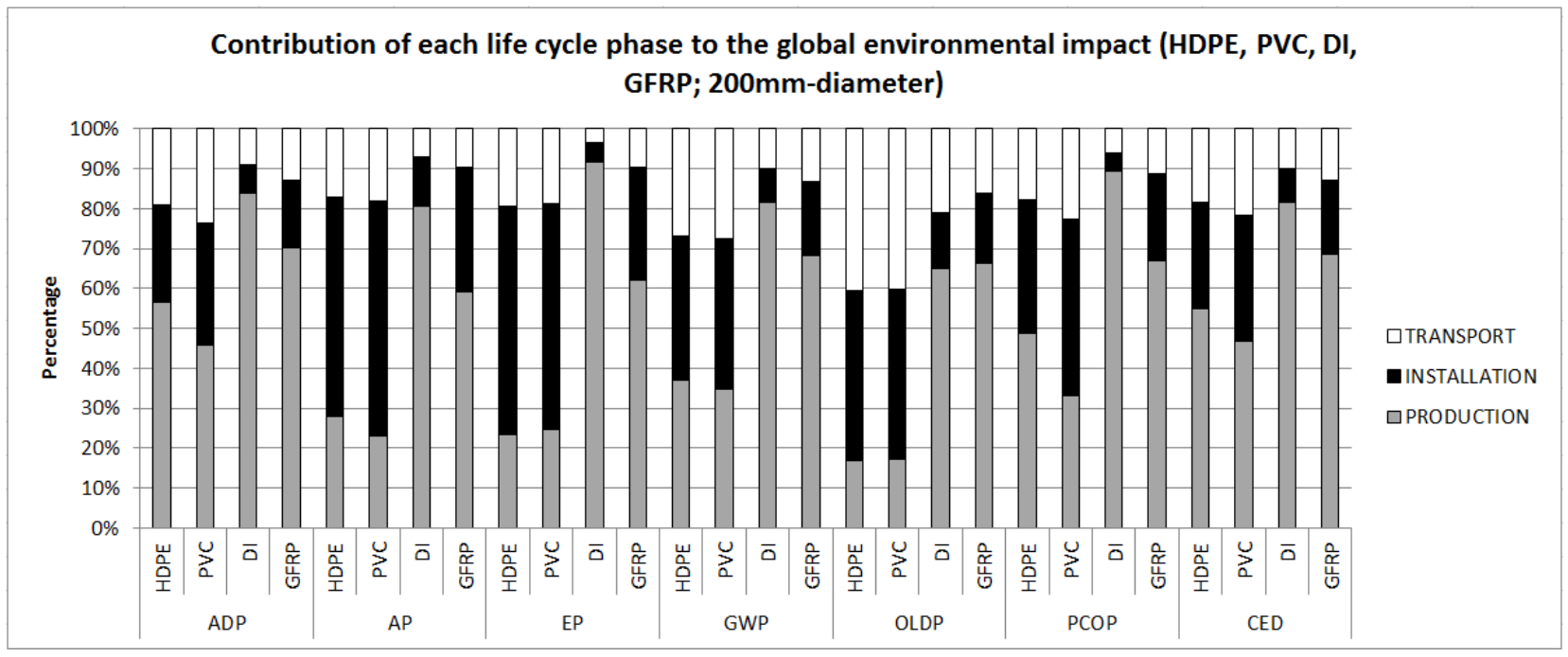

Figure 10. Contribution of each life cycle stage to the environmental impact of $200 \mathrm{~mm}$ diameter pipes

$\mathrm{HDPE}=$ high density polyethylene, $\mathrm{PVC}=$ poly vinyl chloride, $\mathrm{DI}=$ ductile iron, GFRP=glass fibre reinforced polyester

\subsection{Environmental impact of the materials and processes}

Table 4 shows the environmental impacts of each element of the life cycle. The most relevant contributors to the impact of the HDPE $90 \mathrm{~mm}$ pipe diameter solution are the diesel consumption for the installation (24-66\%) and the transport of the backfilling material (19-40\%). Thus, the optimisation of the dimensions of the ditch and the process of installation should be assessed by detecting possible improvements to reduce the environmental impact. LDPE and PVC $90 \mathrm{~mm}$ diameter pipes have not been included in Table 4 because they show similar environmental impacts to the ones presented for HDPE.

In the case of the $200 \mathrm{~mm}$ diameter HDPE pipes, in contrast with the results for the 90 $\mathrm{mm}$ diameter pipes, the material of the pipe (HDPE) doubles the percentage of contribution to the environmental impact of the whole life cycle (up to 50\%). Diesel and the transport by lorries of sand and gravel for backfilling are still significant contributors, with 15 to $40 \%$ of the impact. In this case, although the installation phase also has great relevance, it is also important to consider the pipe itself to reduce the environmental impact. $200 \mathrm{~mm}$ diameter PVC-pipe constructive solution presents similar environmental impacts and is not included in Table 4.

For the $200 \mathrm{~mm}$ diameter GFRP pipe, the main contributors are the consumption of GFRP (30 to $60 \%$ of the environmental impact) and its manufacturing (8 to $33 \%$ ). In this case, the installation and transport phases have minor importance because most of the impact in all impact categories is focused in the production phase. The $200 \mathrm{~mm}$ diameter DI pipe constructive solution presents similar results, with between 65 and 
$90 \%$ of the whole environmental impact from the consumption of DI and the manufacturing of the pipe. These two cases accentuate the importance of the pipe material for greater diameters because the pipe represents a higher percentage of the environmental impact of the constructive solution, whereas the impact of the installation is smaller.

Table 4. Environmental impacts of each material and process for $1 \mathrm{~m}$ of network of $90 \mathrm{~mm}$ and $200 \mathrm{~mm}$ diameter HDPE and 200 mm diameter GFRP pipes.

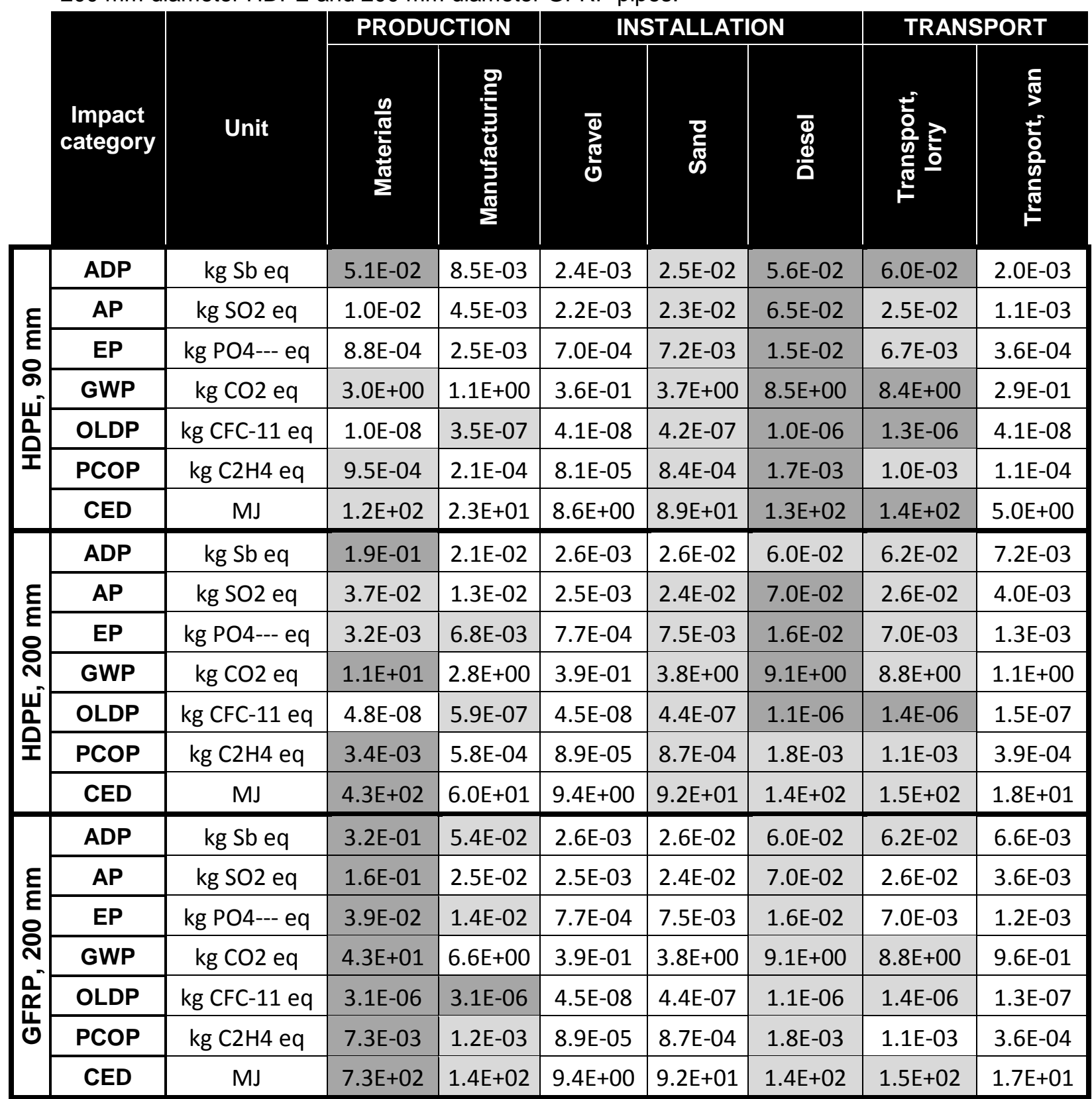

HDPE=high density polyethylene, GFRP=glass fibre reinforced polyester

\subsection{Analysis of a case study DWTDN}

The municipality of Betanzos has been selected as a case study to apply the methodology proposed in the present study. Betanzos is a small inland city located in the northwest of Spain; Table 5 shows its basic data.

Table 5. Basic data about Betanzos (Spain) 


\begin{tabular}{|l|c|}
\hline \multicolumn{1}{|c|}{ Data field } & Betanzos \\
\hline Inhabitants & 13,565 \\
\hline Surface $\left(\mathrm{km}^{2}\right)$ & 24.19 \\
\hline Density of population (inhab./km²) & 561 \\
\hline Climate & Atlantic \\
\hline Precipitation (mm/year) & 1,058 \\
\hline Water consumption ( $\mathrm{m}^{3} /$ inhab·year) & 110 \\
\hline $\begin{array}{l}\text { Electricity consumption to supply the } \\
\text { drinking water (kWh/ inhabitant) }\end{array}$ & 2.79 \\
\hline Length of the DWTDN (km) & 123.5 \\
\hline
\end{tabular}

Source: INE, 2012; Agbar, 2013

This city has been selected because it is small (the methodology is for small to medium cities) and its DWTDN has been renewed lately, so the pipe materials of the network are commonly used.

Table 6 shows the length of each type of pipe in the DWTDN of Betanzos and the percentage they represent.

The table shows that the pipe material with a longer distance of network is HDPE, accounting for $50 \%$ of the network, followed by LDPE (19\%) and PVC (17\%). There is a lot of heterogeneity in the diameters. Most of the network has pipes with diameters between 40 and $125 \mathrm{~mm}$ (approximately 90\%).

The percentage of the pipe materials and diameters in the DWTDN varies depending on the specific case. For example, the pipe materials are very different depending on the country (Graty, 2007) and how recently the network has been renewed.

Table 6. Length of each type of pipe and percentage of the total length (per material and diameter) for the network of Betanzos

\begin{tabular}{|c|c|c|c|}
\hline & Diameter $^{1}(\mathrm{~mm})$ & Length ( $m$ ) & $\%$ \\
\hline \multirow{5}{*}{ HDPE } & 63 & 25,527 & 21.3 \\
\hline & 75 & 6,668 & 5.55 \\
\hline & 90 & 14,105 & 11.8 \\
\hline & 110 & 12,388 & 10.3 \\
\hline & 160 & 2,278 & 1.90 \\
\hline \multirow{3}{*}{ LDPE } & 32 & 1,723 & 1.44 \\
\hline & 40 & 7,769 & 6.47 \\
\hline & 50 & 13,375 & 11.1 \\
\hline \multirow{4}{*}{ PVC } & 90 & 3,649 & 3.04 \\
\hline & 110 & 7,870 & 6.56 \\
\hline & 125 & 5,397 & 4.50 \\
\hline & 160 & 3,822 & 3.18 \\
\hline DI & 100 & 1,585 & 1.32 \\
\hline \multirow{3}{*}{ FC } & 50 & 2,192 & 1.83 \\
\hline & 80 & 2,027 & 1.69 \\
\hline & 150 & 1,624 & 1.35 \\
\hline
\end{tabular}

${ }^{1}$ Diameters that represent less than $1 \%$ of the network are not shown because they are not included in the assessment. HDPE=high density polyethylene, LDPE= low density polyethylene, $\mathrm{PVC}=$ poly vinyl chloride, $\mathrm{DI}=$ ductile iron, $\mathrm{FC}=$ fibre cement

Source: Agbar, 2013 
The environmental impact per lineal meter has been calculated for each type of pipe, and the results obtained have been used together with data from Table 6 to calculate the environmental impact of the Betanzos DWTDN (Table 7). The table shows that the material of pipe that contributes the most to the environmental impact is HDPE (more than $40 \%$ for all impact categories), followed by LDPE and PVC (10 to $40 \%$ ). This is because these materials are the most common along the DWTDN $(51 \%$ of the network HDPE and 19\% LDPE and PVC). Remarkably, the individual elements (hydrants, pumps and valves) that were considered generate between 16 and $17 \%$ of the environmental impact for EP and PCOP.

Table 7. Total environmental impact of the Betanzos network

\begin{tabular}{|c|c|c|c|c|c|c|c|c|}
\hline & & \multicolumn{7}{|c|}{ Environmental impact } \\
\hline $\begin{array}{l}\text { Impact } \\
\text { category }\end{array}$ & Unit & HDPE & LDPE & PVC & DI & $\begin{array}{l}\text { Fibre } \\
\text { cement }\end{array}$ & $\begin{array}{l}\text { Individual } \\
\text { elements }\end{array}$ & TOTAL \\
\hline ADP & $\mathrm{kg} \mathrm{Sb} \mathrm{eq}$ & $1.3 \mathrm{E}+04$ & $3.9 E+03$ & $4.2 \mathrm{E}+03$ & $1.0 \mathrm{E}+03$ & $1.2 \mathrm{E}+03$ & $1.62 \mathrm{E}+03$ & $2.5 \mathrm{E}+04$ \\
\hline AP & $\mathrm{kg} \mathrm{SO} 2 \mathrm{eq}$ & $8.0 \mathrm{E}+03$ & $2.8 \mathrm{E}+03$ & $2.7 \mathrm{E}+03$ & $6.7 \mathrm{E}+02$ & $9.4 \mathrm{E}+02$ & $9.63 E+02$ & $1.6 \mathrm{E}+04$ \\
\hline EP & kg PO4--- eq & $2.0 \mathrm{E}+03$ & $7.2 \mathrm{E}+02$ & $7.2 \mathrm{E}+02$ & $4.0 \mathrm{E}+02$ & $2.4 \mathrm{E}+02$ & $6.91 \mathrm{E}+02$ & $4.8 \mathrm{E}+03$ \\
\hline GWP & $\mathrm{kg} \mathrm{CO} 2 \mathrm{eq}$ & $1.6 \mathrm{E}+06$ & $5.3 E+05$ & $5.5 \mathrm{E}+05$ & $1.3 \mathrm{E}+05$ & $1.9 \mathrm{E}+05$ & $2.01 \mathrm{E}+05$ & $3.2 \mathrm{E}+06$ \\
\hline OLDP & kg CFC-11 eq & $2.0 \mathrm{E}-01$ & $6.8 \mathrm{E}-02$ & $6.7 \mathrm{E}-02$ & $1.0 \mathrm{E}-02$ & $2.1 \mathrm{E}-02$ & $1.14 \mathrm{E}-02$ & $3.8 \mathrm{E}-01$ \\
\hline PCOP & $\mathrm{kg} \mathrm{C} 2 \mathrm{H} 4 \mathrm{eq}$ & $3.0 \mathrm{E}+02$ & $9.3 \mathrm{E}+01$ & $9.6 \mathrm{E}+01$ & $4.8 \mathrm{E}+01$ & $3.6 \mathrm{E}+01$ & $8.48 E+01$ & $6.6 \mathrm{E}+02$ \\
\hline CED & MJ & $3.2 \mathrm{E}+07$ & $9.9 \mathrm{E}+06$ & $1.1 \mathrm{E}+07$ & $2.3 E+06$ & $3.0 \mathrm{E}+06$ & $3.45 \mathrm{E}+06$ & $6.1 \mathrm{E}+07$ \\
\hline
\end{tabular}

$>40 \%$ of the global impact

$10-40 \%$ of the global impact

$<10 \%$ of the global impact

$\mathrm{HDPE}=$ high density polyethylene, $\mathrm{LDPE}=$ low density polyethylene, $\mathrm{PVC}=$ poly vinyl chloride, $\mathrm{DI}=$ ductile iron

Table 8 shows the environmental impact of the DWTDN of Betanzos converted to $\mathrm{m}^{3}$.year and to other units. Further research on this field or the application of this methodology to other case studies might provide new data that could be compared with the results.

The estimated scenario shows that a potential reduction of between 6 and $16 \%$ of the total environmental impact can be achieved. This shows the importance of the selection of one or another pipe material for the reduction of the environmental impact. It must be stated that the actual network of Betanzos is mainly built using HDPE, LDPE and PVC pipes (90\% of the network). Thus, the difference of impact between these pipes and PVC pipes is small. The application to other case studies with a DWTDN with more impacting pipes might present higher percentages of reduction.

The methodology proposed can be applied to any grid as far as the length of each type of pipe and the individual elements are known. This methodology allows the designers of the DWTDN to calculate the environmental impact derived from the network, which is useful for decision making during the design of the network. 
Table 8. Actual environmental impact of the Betanzos DWTDN and estimation of the potential impact reduction.

\begin{tabular}{|c|c|c|c|c|c|c|c|c|c|c|}
\hline & & \multicolumn{4}{|c|}{ Actual environmental impact } & \multicolumn{4}{|c|}{ Estimated environmental impact } & \multirow[b]{2}{*}{$\begin{array}{c}\% \\
\text { reduction }\end{array}$} \\
\hline $\begin{array}{l}\text { Impact } \\
\text { category }\end{array}$ & Unit & $\begin{array}{c}\text { per } m^{3} \text { of } \\
\text { water-year }\end{array}$ & total. year & $\begin{array}{c}\text { per } \\
\text { inhabitant } \\
\text { year }\end{array}$ & $\begin{array}{c}\text { per } m \text { of } \\
\text { DWTDN. } \\
\text { year }\end{array}$ & $\begin{array}{c}\text { per } \mathbf{m}^{3} \text { of } \\
\text { water-year }\end{array}$ & total year & $\begin{array}{c}\text { per } \\
\text { inhabitant } \\
\text { year }\end{array}$ & $\begin{array}{l}\text { per } m \text { of } \\
\text { DWTDN. } \\
\text { year }\end{array}$ & \\
\hline ADP & kg Sb eq & 4.4E-04 & $4.9 \mathrm{E}+02$ & 3.6E-02 & 4.1E-03 & $3.8 \mathrm{E}-04$ & $4.3 \mathrm{E}+02$ & 3.2E-02 & $3.6 \mathrm{E}-03$ & -13 \\
\hline AP & $\mathrm{kg} \mathrm{SO} 2 \mathrm{eq}$ & 2.9E-04 & $3.2 \mathrm{E}+02$ & $2.4 \mathrm{E}-02$ & 2.7E-03 & 2.6E-04 & $3.0 \mathrm{E}+02$ & 2.2E-02 & $2.5 \mathrm{E}-03$ & -8 \\
\hline EP & kg PO4--- eq & $8.5 \mathrm{E}-05$ & $9.6 \mathrm{E}+01$ & $7.1 \mathrm{E}-03$ & 8.0E-04 & 7.7E-05 & $8.6 \mathrm{E}+01$ & $6.4 \mathrm{E}-03$ & $7.2 \mathrm{E}-04$ & -10 \\
\hline GWP & $\mathrm{kg} \mathrm{CO} 2 \mathrm{eq}$ & $5.6 \mathrm{E}-02$ & $6.3 \mathrm{E}+04$ & $4.7 \mathrm{E}+00$ & 5.3E-01 & $5.1 \mathrm{E}-02$ & $5.8 \mathrm{E}+04$ & $4.3 \mathrm{E}+00$ & $4.8 \mathrm{E}-01$ & -9 \\
\hline OLDP & kg CFC-11eq & 6.7E-09 & $7.5 \mathrm{E}-03$ & $5.6 \mathrm{E}-07$ & $6.3 \mathrm{E}-08$ & $6.3 \mathrm{E}-09$ & 7.1E-03 & $5.2 \mathrm{E}-07$ & $5.9 \mathrm{E}-08$ & -6 \\
\hline PCOP & $\mathrm{kg} \mathrm{C} 2 \mathrm{H} 4 \mathrm{eq}$ & $1.2 \mathrm{E}-05$ & $1.3 \mathrm{E}+01$ & 9.7E-04 & $1.1 \mathrm{E}-04$ & $9.8 \mathrm{E}-06$ & $1.1 \mathrm{E}+01$ & $8.2 E-04$ & $9.2 \mathrm{E}-05$ & -16 \\
\hline CED & MJ & $1.1 \mathrm{E}+00$ & $1.2 \mathrm{E}+06$ & $9.0 \mathrm{E}+01$ & $1.0 \mathrm{E}+01$ & 9.6E-01 & $1.1 \mathrm{E}+06$ & $8.0 \mathrm{E}+01$ & $9.0 \mathrm{E}+00$ & -11 \\
\hline
\end{tabular}

DWTDN=drinking water transport and distribution network 


\section{Conclusions}

The whole constructive solution of the DWTDN must be considered in order to not to omit the environmental impacts of the materials transport and installation phases, which can represent between 60 and $90 \%$ of the environmental impacts in all the impact categories for smaller (90 $\mathrm{mm}$ diameter) pipes. To reduce the impact, the constructive solutions of the network must not be treated homogeneously. The installation phase is especially relevant for constructive solutions with smaller pipe diameters (more than $40 \%$ of the impact in all the impact categories for $90 \mathrm{~mm}$ diameter HDPE), whereas the production of the pipe becomes more relevant with greater pipe diameters (35\% of the impact in 4 out of 7 impact categories for $200 \mathrm{~mm}$ diameter HDPE). Thus, the reduction of environmental impacts involves the optimisation of the trench dimensions and the process of installation as well as the selection of pipe materials with lower environmental impacts in the production phase.

Further research regarding the lifespan of the different pipe materials might help deciding which the best one is, since for constructive solutions with $90 \mathrm{~mm}$ diameter HDPE, LDPE and PVC pipes have similar environmental impacts. On the other hand, for $200 \mathrm{~mm}$ pipe constructive solutions, GFRP and DI show higher environmental impacts than HDPE and PVC, which in the case of DI are between 3 and 11 times higher than those of HDPE for all the impact categories and $40 \%$ to 1.5 times higher for GFRP. In this case, the production of the pipe material is the most impactful element, especially for DI and GFRP pipes (more than $60 \%$ of the impact in all the impact categories).

Future studies should provide global data about the lifetime of the pipes because the lifetime can significantly influence the environmental impact of each constructive solution. Furthermore, future changes in the management of the network at its end of life (recovering the pipe materials or sending it to landfill) might influence the environmental impact of the constructive solutions.

Most of the network of the case study is formed by pipes made of HDPE (50\%), LDPE $(19 \%)$ and PVC (19\%). Regarding the diameters of the pipes, there is a lot of heterogeneity, but $90 \%$ of the network has diameters between 40 and $125 \mathrm{~mm}$. Substituting all the constructive solutions of the DWTDN for PVC constructive solutions in the pilot case study can reduce the environmental impact from the construction of the network (between 6 and $16 \%$ of the impact). This potential of improvement with the renewal of the network can be greater in DWTDN with more impactful pipe materials such as DI. The materials used are very different depending on the country.

The assessment of the environmental impact of the Betanzos DWTDN consisted of calculating the unitary impacts for each type of pipe and individual element (hydrants, valves and pumps) and multiplying it by the length and number of units of the DWTDN to obtain the environmental impact. This method can be applied to other small to medium cities or neighbourhoods if the length of each type of pipe (diameter and material) and the number of each sort of individual element is known.

The development of a tool based on this methodology would be useful for the environmental design of DWTDN. Constructors and municipal managers could easily estimate the environmental impact of the construction of the network and thus design cleaner networks. 


\section{Acknowledgements}

This research was sponsored by the European LIFE+ programme as part of the AQUAENVEC project "Assessment and improvement of the urban water cycle ecoefficiency use LCA and LCC" on the urban water cycle (LIFE10 ENV/ES/000520).

The authors are grateful for the support of the Spanish Ministry of Education and Science through the project BIA (2010-20789-C04-01).

The authors are also grateful for the support of Spanish Ministry of Education and Science through the project PLUVISOST (CTM2010-17365).

We would like to thank Ramón Creus, the director of the Operative Control Center of Agbar,

for his

personal communications. 


\section{Supplementary data}

Supplementary table $A$. Inventory of the materials and energy per $m$ of network considered for the comparison of the pipes.

\begin{tabular}{|c|c|c|c|c|c|c|c|c|c|c|}
\hline & \multicolumn{3}{|c|}{ Ecoinvent 2.2 process } & \multicolumn{7}{|c|}{ Unit per lineal $\mathbf{m}$} \\
\hline & Material & Processing & $\begin{array}{l}\text { Energy } \\
\text { requirements } \\
\text { (MJ/kg) }\end{array}$ & $\begin{array}{c}\text { HDPE } \\
(90 \\
\mathrm{mm})\end{array}$ & $\begin{array}{l}\text { LDPE } \\
(90 \\
\mathbf{m m})\end{array}$ & $\begin{array}{c}\text { PVC } \\
(90 \\
\mathrm{mm})\end{array}$ & $\begin{array}{l}\text { HDPE } \\
(200 \\
\mathrm{mm})\end{array}$ & $\begin{array}{l}\text { PVC } \\
(200 \\
\mathrm{mm})\end{array}$ & $\begin{array}{c}\text { DI } \\
(200 \\
\mathrm{mm})\end{array}$ & $\begin{array}{l}\text { GFRP } \\
(200 \\
\mathrm{mm})\end{array}$ \\
\hline Pressure (bar) & - & - & & 6 & 6 & 6 & 10 & 10 & 10 & 10 \\
\hline Connections & - & - & & W & $\mathrm{BP}$ & ER & W & ER & $\begin{array}{l}\mathrm{BU}- \\
\mathrm{ER}\end{array}$ & PS \\
\hline Weight (kg) & - & - & & 1.0 & 2.1 & 1.0 & 4.7 & 4.0 & 36.0 & 11.4 \\
\hline $\begin{array}{l}\text { Life expectancy } \\
\text { (years) }\end{array}$ & - & - & & 50 & 50 & 50 & 50 & 50 & 50 & 50 \\
\hline $\mathrm{HDPE}^{1}(\mathrm{~kg})$ & $\begin{array}{l}\text { Polyethylene, HDPE, granulate, at plant/RER } \\
\text { S }\end{array}$ & $\begin{array}{l}\text { Extrusion, plastic pipes/RER } \mathrm{S}^{2} \\
\text { Injection moulding/RER } \mathrm{S}^{3}\end{array}$ & 85 & 1.52 & 0 & 0 & 5.50 & 0 & 0 & 0 \\
\hline LDPE $^{1}(\mathbf{k g})$ & $\begin{array}{l}\text { Polyethylene, LDPE, granulate, at plant/RER } \\
\text { S }\end{array}$ & $\begin{array}{l}\text { Extrusion, plastic pipes/RER } S^{2} \\
\text { Injection moulding/RER } S^{3}\end{array}$ & 88 & 0 & 2.63 & 0 & 0 & 0 & 0 & 0 \\
\hline $\mathrm{PVC}^{1}(\mathrm{~kg})$ & Polyvinylchloride, at regional storage/RER S & $\begin{array}{l}\text { Extrusion, plastic pipes/RER } \mathrm{S}^{2} \\
\text { Injection moulding/RER } \mathrm{S}^{3}\end{array}$ & 69 & 0 & 0 & 1.34 & 0 & 4.76 & 0 & 0 \\
\hline $\mathrm{Dl}^{1}(\mathbf{k g})$ & Cast iron, at plant/RER S & $\begin{array}{l}\text { Metal product manufacturing, } \\
\text { average metal working/RER S }\end{array}$ & 58 & 0 & 0 & 0 & 0 & 0 & 38.8 & 0 \\
\hline GFRP (kg) & $\begin{array}{l}\text { Glass fibre reinforced plastic, polyamide, } \\
\text { injection moulding, at plant/RER S }\end{array}$ & Injection moulding/RER S & 111 & 0 & 0 & 0 & 0 & 0 & 0 & 4.96 \\
\hline $\begin{array}{l}\text { Synthetic } \\
\text { rubber }(\mathrm{kg})\end{array}$ & Synthetic rubber, at plant/RER S & & 91 & 0.0147 & 0.0072 & 0.121 & 0.0696 & 0.101 & 0.245 & 0.0105 \\
\hline Sand (kg) & Sand, at mine/CH S & & 0.058 & 1,530 & 1,530 & 1,530 & 1,590 & 1,590 & 1,590 & 1,590 \\
\hline Gravel (kg) & Gravel, round, at mine/CH S & & 0.058 & 148 & 148 & 148 & 163 & 163 & 163 & 163 \\
\hline $\begin{array}{l}\text { Diesel, } \\
\text { machinery (MJ) }\end{array}$ & Diesel, burned in building machine/GLO S & & $1.4^{*}$ & 92.0 & 92.0 & 92.0 & 99.2 & 99.2 & 99.2 & 99.2 \\
\hline $\begin{array}{l}\text { Transport van } \\
\text { (tkm) }\end{array}$ & Transport, van <3.5t/RER S & & $33^{\star *}$ & 0.152 & 0.263 & 0.135 & 0.550 & 0.487 & 3.91 & 0.497 \\
\hline $\begin{array}{l}\text { Transport lorry } \\
(\mathrm{tkm})\end{array}$ & Transport, lorry 16-32t, EURO5/RER S & & $2.8^{\star \star}$ & 50.5 & 50.5 & 50.5 & 52.5 & 52.5 & 52.5 & 52.5 \\
\hline
\end{tabular}

${ }^{*} \mathrm{MJ} / \mathrm{MJ}$ diesel, ${ }^{* *} \mathrm{MJ} / \mathrm{tkm},{ }^{1}$ Includes the pipe and its accessories made of the same material, ${ }^{2}$ pipe, ${ }^{3}$ accessories

$\mathrm{HDPE}=$ high density polyethylene, $\mathrm{LDPE}=$ low density polyethylene, $\mathrm{PVC}=$ poly vinyl chloride, $\mathrm{Dl}=$ ductile iron, $\mathrm{GFRP}=\mathrm{glass}$ fibre reinforced polyester,

$\mathrm{W}=$ Welded, $\mathrm{BP}=\mathrm{By}$ pressure, $\mathrm{ER}=$ Elastomeric ring, $\mathrm{BU}=$ Bell union, $\mathrm{PS}=$ Polyester sleeve

Source: Metabase Itec, 2010 
Supplementary table B. Inventory of the materials and energy considered for hydrants, pumps and shut-off valves.

\begin{tabular}{|c|c|c|c|c|c|c|c|c|}
\hline & \multicolumn{3}{|c|}{ Ecoinvent 2.2 process } & \multicolumn{5}{|c|}{ kg per unit } \\
\hline & Material & Processing & $\begin{array}{l}\text { Energy } \\
\text { requirements } \\
(\mathrm{MJ} / \mathrm{kg})\end{array}$ & $\begin{array}{l}\text { Hydrant, } \\
100 \mathrm{~mm}\end{array}$ & $\begin{array}{l}\text { Pump, } \\
35 \\
\mathrm{~m}^{3} / \mathrm{h}\end{array}$ & $\begin{array}{l}\text { Pump, } \\
60 \\
\mathrm{~m}^{3} / \mathrm{h}\end{array}$ & $\begin{array}{c}\text { Shut-off } \\
\text { valve, } 50 \\
\text { mm }\end{array}$ & $\begin{array}{l}\text { Shut-off } \\
\text { valve, } 100 \\
\text { mm }\end{array}$ \\
\hline Steel & $\begin{array}{l}\text { Steel, low-alloyed, at } \\
\text { plant/RER S }\end{array}$ & $\begin{array}{l}\text { Metal product manufacturing, } \\
\text { average metal working/RER } \\
\text { S }\end{array}$ & 61 & - & 3.5 & 16.5 & 1.9 & 4.5 \\
\hline Cast Iron & $\begin{array}{l}\text { Cast iron, at plant/RER } \\
\mathrm{S}\end{array}$ & $\begin{array}{l}\text { Metal product manufacturing, } \\
\text { average metal working/RER } \\
\text { S }\end{array}$ & 58 & 168 & 31.5 & 148.5 & 10.5 & 25.2 \\
\hline $\begin{array}{l}\text { Galvanised } \\
\text { steel }\end{array}$ & $\begin{array}{l}\text { Steel, low-alloyed, at } \\
\text { plant/RER S }\end{array}$ & $\begin{array}{l}\text { Metal product manufacturing, } \\
\text { average metal working/RER } \\
\text { S }\end{array}$ & 61 & 0.2 & - & - & - & - \\
\hline $\begin{array}{l}\text { Epoxy } \\
\text { resin }\end{array}$ & $\begin{array}{l}\text { Epoxy resin, liquid, at } \\
\text { plant/RER S }\end{array}$ & - & 135 & 0.3 & - & - & - & - \\
\hline $\begin{array}{l}\text { Synthetic } \\
\text { rubber }\end{array}$ & $\begin{array}{l}\text { Synthetic rubber, at } \\
\text { plant/RER S }\end{array}$ & - & 91 & - & - & - & 0.13 & 0.3 \\
\hline
\end{tabular}

Source: Metabase Itec, 2010 


\section{References}

Adequa Uralita. (2010). Prontuario. Instalación de tuberías para abastecimiento, riego y saneamiento según normativa vigente. PDF document retrieved from http://www.adequa-

tuberias.com/tarifasDocumentacion/documentos/Lists/Info\%20Documentos/Attach ments/4/prontuario-2010.pdf

Agbar (C. <http://www.agbar.es/en/home.html> [Accessed on September 2013]

Amores, M. J., Meneses, M., Pasqualino, J., Antón, A., Castells, F. 2013. Environmental assessment of urban water cycle on Mediterranean conditions by LCA approach. Journal of Cleaner Production, 43, 84-92.

Arpke, A., Hutzler, N. 2006. Domestic Water Use in the United States. Journal of Industrial Ecology 10(1), 169-184.

American Water Works Association (AWWA). Plastic Pipe Institute. 2010. The lifecycle of current HDPE pipes in potable water applications. Retrieved from http://www.awwa-

hi.org/2_archives/10conf/presentations/2010\%20AWWA\%20Life\%20Cycle\%20HD PE\%20in\%20PW\%20Apps\%20Camille\%20Rubeiz.pdf

American Water Works Association (AWWA). 2011. The Epidemic of Corrosion, Part 1: Examining Pipe Life. Journal AWWA, December 2011. Retrieved from http://www.agingwaterinfrastructure.org/SiteResource/Site_109155/Customize/Im age/file/Alternative\%20Materials\%20and\%20Project\%20Delivery\%20Methods/AW WA\%20Dec\%202011\%20The\%20Epidemic\%20of\%20Corrosion\%20Part\%201\%2 0Examining\%20Pipe\%20Life.pdf

CEDEX, Centro de Estudios Hidrográficos. 2009. Guía Técnica sobre tuberías para el transporte de agua a presión. $6^{\text {th }}$ edition, ISBN:978-84-7790-492-2

CONTEC, Control Técnico del Ciclo Integral del Agua, 2012 (C) Aqualogy Services Company

Dennison, F. J., Azapagic, A., Clift, R., Colbourne, J. S. 1999. Life cycle assessment: comparing strategic options for the mains infrastructure-Part I. Water Science \& Technology, 39(10), 315-319.

ecoinvent. 2009. Swiss Centre for Life Cycle Inventories. ecoinvent database v3.0. $<\mathrm{http}: / /$ www.ecoinvent.ch/> [Accessed on January 2013].

EN 15804. European Committee for Standardization. 2011. Sustainability of construction works - Environmental product declarations - Core rules for the product category of construction product.

Fagan, J. E., Reuter, M. A., Langford, K. J. 2010. Dynamic performance metrics to assess sustainability and cost effectiveness of integrated urban water systems. Resources, Conservation and Recycling, 54(10), 719-736.

Faria, H., Guedes, R. M. 2010. Long-term behaviour of GFRP pipes: Reducing the prediction test duration. Polymer Testing, 29(3), 337-345. 
Friedrich, E., Pillay, S., Buckley, C. A. 2009. Carbon footprint analysis for increasing water supply and sanitation in South Africa: a case study. Journal of Cleaner Production, 17(1), 1-12.

Graty, R. TEPPFA European Pipe Survey. (2007). First European pipe survey of existing networks. PDF document retrieved from

http://www.teppfa.org/pdf/ABSORPTIONFINAL.pdf

GISAgua. 2012. (C) Aqualogy Services Company

Institut de Tecnología de la Construcció de Catalunya. Metabase (Itec Database). Retrieved from http://www.itec.es/nouBedec.e/bedec.aspx [Accessed on Mars 2013]

Instituto Nacional de Estadística (INE). 2012. Población, superfície y densidad por municipios. Retrieved from http://www.ine.es/jaxi/tabla.do [Accessed on May 2013]

Krook, J., Eklund, M., Carlsson, A., Frändegård, P., Svensson, N. 2010. Urban miningProspecting for metals in the invisible city. ERSCP-EMSU conference, Delft, The Netherlands, October 25-29, 2010.

Lassaux, S., Renzoni, R., Germain, A. 2007. Life cycle assessment of water from the pumping station to the wastewater treatment plant. International Journal of Life Cycle Assessment, 12(2), 118.

Lemos, D., et al., Environmental assessment of an urban water system, Journal of Cleaner Production (2013), http://dx.doi.org/10.1016/j.jclepro.2013.04.029

Mendoza, J. M. F., Oliver-Solà, J., Gabarrell, X., Rieradevall, J., \& Josa, A. 2012. Planning strategies for promoting environmentally suitable pedestrian pavements in cities. Transportation research part D: transport and environment, 17(6), 442450.

Metabase Itec, 2010. Online ITeC database: prices, technical details, companies, certificates, product pictures and environmental data. Retrieved from http://www.itec.cat/metabase. [Accessed on September 2013]

Muñoz, I., Milà-i-Canals, L., Fernández-Alba, A. R. 2010. Life Cycle Assessment of Water Supply Plans in Mediterranean Spain. Journal of Industrial Ecology, 14(6), 902-918.

Oliver-Solà, J., Josa, A., Rieradevall, J., \& Gabarrell, X. (2009). Environmental optimization of concrete sidewalks in urban areas. The International Journal of Life Cycle Assessment, 14(4), 302-312.

Piratla, K. R., Ariaratnam, S. T., Cohen, A. 2012. Estimation of CO 2 emissions from the life cycle of a potable water pipeline project. Journal of Management in Engineering, 28(1), 22-30.

PRé Consultants. (2010). Simapro 7.2.0. Amersfoort (Nederlands) 
Racoviceanu, A. I., Karney, B. W., Kennedy, C. A., Colombo, A. F. 2007. Life-cycle energy use and greenhouse gas emissions inventory for water treatment systems. Journal of infrastructure systems, 13(4), 261-270.

Sharma, A. K., Grant, A. L., Grant, T., Pamminger, F., Opray, L. 2009. Environmental and Economic Assessment of Urban Water Services for a Greenfield Development. Environmental Engineering Science, 26(5), 921-934.

Stokes, J., Horvath, A. 2006. Life Cycle Energy Assessment of Alternative Water Supply Systems. Int J LCA 11 (5) 335 - 343.

Stokes, J. R., Horvath, A. 2009. Energy and air emission effects of water supply. Environmental science \& technology, 43(8), 2680-7.

Stokes, J., Horvath, A. 2010. Life-cycle assessment of urban water provision: Tool and case study in California. Journal of Infrastructure Systems, 17(1), 15-24.

United Nations Educational, Scientific, and Cultural Organization (UNESCO). 2012. Managing Water under Uncertainity and Risk. The United Nations World Water Development Report 4. Volume 1. PDF document retrieved from http://www.unesco.org/new/en/naturalsciences/environment/water/wwap/wwdr/wwdr4-2012/

Venkatesh, G., Brattebø, H. 2011. Energy consumption, costs and environmental impacts for urban water cycle services: Case study of Oslo (Norway). Energy, 36(2), 792-800.

Venkatesh, G., Brattebø, H. 2012. Assessment of Environmental Impacts of an Aging and Stagnating Water Supply Pipeline Network. Journal of Industrial Ecology, 16(5), 722-734.

Vince, F., Aoustin, E., Bréant, P., Marechal, F. 2008. LCA tool for the environmental evaluation of potable water production. Desalination, 220(1-3), 37-56. 